\title{
Peramalan Daerah Fishing Ground di Perairan Pulau Weh, Kota Sabang Menggunakan Indikator Suhu Permukaan Laut dan Klorofil-a Serta Hubungannya Dengan Kelimpahan Ikan Tongkol
}

\author{
Teuku Fauzan Zul Aufar ${ }^{1}$, Kunarso ${ }^{1}$, Lilik Maslukah ${ }^{1 *}$, Dwi Haryo Ismunarti ${ }^{1}$ dan \\ Anindya Wirasatriya ${ }^{1}$
}

\author{
${ }^{1}$ Departemen Oseanografi, Jurusan Ilmu Kelautan Fakultas Perikanan dan Ilmu Kelautan \\ Jl. Prof. H. Sudarto, SH Tembalang, Telp/fax (024) 7474698 Semarang 50275 \\ *Email:Lilik_masluka@gmail.com
}

\begin{abstract}
Abstrak
Fishing ground atau zona penangkapan ikan adalah suatu kawasan perairan yang menjadi sasaran penangkapan ikan. Prediksi zona tangkapan ikan dapat dilakukan dengan cara mendeteksi sebaran klorofil-a dan sebaran suhu permukaan laut (SPL) dari citra Aqua MODIS. Penelitian ini bertujuan mempelajari perkiraan potensi daerah fishing ground pada variasi monsun di perairan Pulau Weh Kota Sabang dan hubungannya dengan kelimpahan ikan tongkol. Data SPL dan klorofil-a yang digunakan didapatkan dari citra MODIS. Hasil penelitian menunjukkan bahwa pada monsun Barat-Peralihan I yang terjadi pada Bulan Desember, Januari, Februari, Maret, April, dan Mei merupakan musim dengan jumlah tangkapan ikan tinggi. Bulan Februari merupakan puncak tertinggi hasil tangkapan, dengan luas area tangkapan diprediksi mencapai 455,89 $\mathrm{km}^{2}$. Jumlah hasil tangkapan tongkol tertinggi ditemukan pada musim Barat dan kondisi ini bersamaan dengan tingginya konsentrasi klorofil-a dan rendahnya nilai SPL. Musim Timur-peralihan II yang terjadi pada Bulan Juni, Juli, Agustus, September, Oktober, dan November merupakan musim dengan tangkapan tongkol rendah. Bulan Juni memiliki hasil tangkapan ikan tongkol paling rendah, dan dari hasil prediksi penentuan daerah potensi fishing ground diperkirakan hanya mencapai $190,19 \mathrm{~km}^{2}$. Lokasi prediksi fishing ground pada musim Barat-peralihan I dominan disebelah timur Pulau Weh, Provinsi Aceh dan sebaliknya pada musim Timur sampai peralihan II, lokasi fishing ground dominan di sebelah Barat Pulau Weh.
\end{abstract}

Kata Kunci: Fishing Ground, Ikan Tongkol, Pulau Weh, Sabang

\begin{abstract}
Fishing ground is a water area that is the target of fishing. Prediction of fishing ground can be done by determining the distribution of chlorophyll-a and SST from the Aqua MODIS image. This study aims to determine the fishing ground area in monsoon variations in the sea waters of Weh Island, Sabang City and its relationship with the abundance of mackarel tuna. The SST and chlorophyll-a data used were obtained from MODIS images. The results showed that the West-Transitional I monsoon which occurred in December, January, February, March, April, and May was the season with the highest number of fish catches. February is the highest peak of catch, with a predicted catchment area of $455.89 \mathrm{~km}^{2}$. The highest number of mackarel tuna catches was found in the West season and this condition coincided with high concentrations of chlorophyll-a and low SST values. East-transition II season that occurs in June, July, August, September, October, and November is a season with low mackarel tuna catches. The month of June has the lowest mackarel tuna catch, and from the prediction results of determining the potential fishing ground area it is estimated to only reach $190.19 \mathrm{~km} 2$. The predicted location for fishing ground in the West season to transition I is dominant in the east of Weh Island, Aceh Province and vice versa in the rainy season. East to transition II, the dominant fishing ground location is in the west of Pulau Weh.
\end{abstract}

Keywords : Fishing Ground, Mackarel Tuna, Weh Island, Sabang

\section{PENDAHULUAN}

Perairan Utara Provinsi Aceh merupakan perairan yang berhubungan dengan Samudra Hindia yang memiliki potensi sumberdaya perikanan yang cukup besar, sehingga usaha penangkapan ikan 
sangat baik untuk dikembangkan. Ikan cakalang dan tongkol merupakan komoditas sumberdaya perikanan yang bernilai ekonomis penting di perairan Utara Provinsi Aceh (Muklis et al., 2009).

Faktor penentu keberhasilan dalam usaha penangkapan ikan salah satunya adalah kemampuan dalam menentukan daerah penangkapan ikan (fishing ground) sebelum dilakukan operasi penangkapan ikan. Pada umumnya nelayan menentukan daerah penangkapan ikan berdasarkan intuisi/insting dan pengalaman lapangan sehingga kurang efektif karena adanya ketidakpastian yang cukup tinggi sehingga hasil tangkapan sulit untuk diprediksi. Prediksi daerah yang potensial untuk penangkapan ikan dapat dilakukan melalui pengkajian parameter-parameter oseanografi yang berhubungan dengan keberadaan ikan. Suhu dan konsentrasi klorofil-a merupakan parameter oseanografi yang berpengaruh bagi keberadaan sumberdaya ikan (Gaol, et al., 2004).

Beberapa paramater yang dapat digunakan sebagai pendugaan daerah penangkapan ikan adalah melalui indikator Suhu Permukaan Laut (SPL) dan konsentrasi klorofil-a. Distribusi SPL dan klorofil-a ini dapat dideteksi dengan teknik penginderaan jauh, yaitu dengan menggunakan data citra satelit Aqua dengan sensor Moderate Resolution Imaging Spectroradiometer (MODIS) (Girsang, 2008).

Beberapa penelitian penentuan daerah fishing ground di Perairan Aceh menggunakan indikator SPL dan klorofil-a telah dilakukan sebelumnya, antara lain oleh Habib et al. (2019) yaitu pada ikan cakalang di perairan Aceh, Muklis et al. (2009) di perairan Utara Nanggroe Aceh Darussalam, dan Mursyidin et al. (2015) di Perairan Aceh Jaya. Penelitian penentuan fishing ground pada Pulau Weh, Kota Sabang, secara khusus belum pernah dilakukan oleh peneliti sebelumnya. Mengingat penentuan potensi daerah fishing ground sangat penting dalam keberhasilan penangkapan ikan, sehingga perlu dilakukan penelitian, khususnya untuk wilayah Pulau Weh, Kota Sabang. Penelitian potensi prediksi fishing ground ini dilakukan menggunakan parameter data SPL dan klorofil-a. Diharapkan hasil penelitian dapat digunakan sebagai bahan pertimbangan dalam penangkapan ikan pada umumya dan pada ikan tongkol pada khususnya.

\section{MATERI DAN METODE}

Materi penelitian yang digunakan dalam penelitian ini berupa data utama dan data penunjang. Data utama yang digunakan adalah data citra satelit Aqua MODIS berupa data klorofil-a dan suhu permukaan laut (SPL). Data penunjang meliputi data angin dari European Centre for Medium-Range Weather Forecasts (ECMWF), data hasil tangkapan tongkol nelayan, dan citra Google Earth.

Penelitian ini menggunakan metode kuantitatif, yaitu metode yang bersifat realistis dan dapat diklasifikasikan konkrit teramati, serta terukur. Metode ini memiliki karakteristik desain yang spesifik, jelas, rinci, ditentukan secara mantap sejak awal, dan menjadi pegangan langkah demi langkah. Metode kuantitatif memiliki tujuan untuk menunjukan hubungan antar variabel, menguji teori, mencari generalisasi yang mempunyai nilai prediktif (Suryana, 2010).

Penentuan lokasi sampling menggunakan metode purposive sampling. Menurut Sugiyono (2010) purposive sampling merupakan penentuan sampel penelitian dengan beberapa pertimbangan tertentu dari peneliti yang bertujuan agar data yang diperoleh nantinya bisa lebih representatif. Dalam penentuan lokasi sampling ikan memperhatikan beberapa hal, antara lain : diperkirakan merupakan daerah peramalan yang mempunyai potensi ikan tinggi dan dipilih daerah yang dilalui pola dari ruaya ikan (Kunarso, 2005). Peta lokasi penelitian dapat disajikan Gambar 1. 


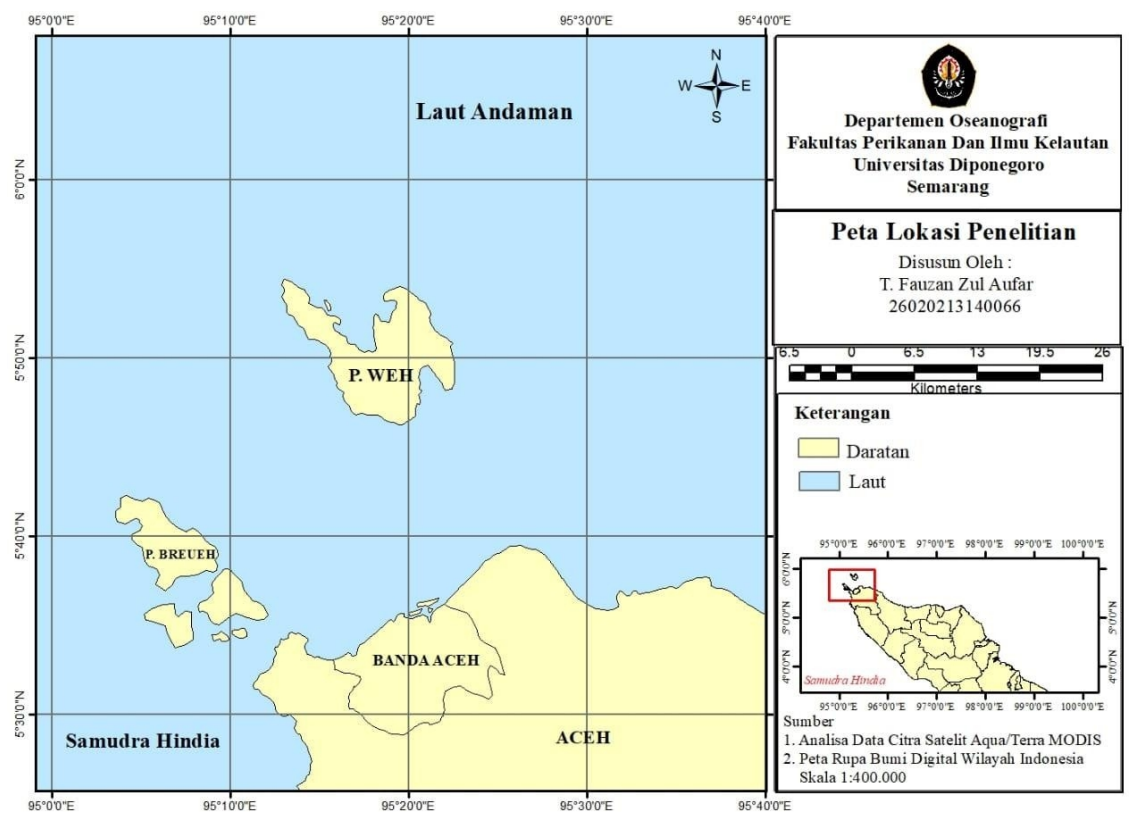

Gambar 1. Peta Lokasi Peneitian.

\section{Pengolahan Data Klorofil-a :}

Data klorofil-a didapatkan melalui pengolahan data citra satelit klorofil-a Aqua MODIS, menggunakan software SeaDAS dan selanjutnya pola sebarannya menggunakan software ArcGIS.

\section{Pengolahan Data Citra SPL}

Data suhu permukaan laut didapatkan dari citra satelit Aqua MODIS, dan pola sebarannya menggunakan software ArcGIS. Selanjutnya data SPL dan klorofil-a di overlay menggunakan software ArcGIS. Citra satelit Aqua MODIS yang digunakan dalam penelitian ini adalah level 3. Algoritma yang digunakan adalah algoritma standar yang terdapat dalam perangkat lunak SeaDAS. Muklis et al. (2009) menjelaskan bahwa Citra level 3 sudah terkoreksi secara radiometrik dan geometrik dalam format Hierachical Data Format (HDF).

\section{Pengolahan Data Angin}

Data angin dalam penelitian ini diperoleh dari European Centre for Medium-Range Weather Forecasts (ECMWF) berupa data rata-rata bulanan dengan resolusi spasial 0,125 x 0,125 dalam format NET Common Data File (NetCdF) selama periode 11 tahun (tahun 2006 sampai 2016), diunduh dari website ECMWF. Data angin yang digunakan terdiri dari komponen angin zonal (u) dalam arah Timur-Barat atau bujur dan meridional (v) dalam arah Utara-Selatan atau lintang yang berupa data kecepatan dalam satuan knot dan data arah dalam satuan derajat. Data angin yang diperoleh dari ECMWF diekstrak menggunakan software SeaDAS. Data angin selanjutnya diolah menggunakan Microsoft excel untuk mendapatkan nilai rata-rata kecepatan total dan arah total pada wilayah kajian dan selanjutnya ditampilkan dalam bentuk windrose untuk melihat arah angin yang terjadi pada tiap bulan dari tahun 2006 sampai 2016.

\section{Pengolahan Citra Fishing Ground}

Hasil overlay antara data klorofil-a dan suhu permukaan laut, maka peta prediksi fishing ground dapat dihasilkan. Menurut BPOL (2016), citra klorofil-a diidentifikasi dengan pengelompokan pixel pada citra tersebut yang memiliki nilai $0,2-1 \mathrm{mg} / \mathrm{m}^{3}$ dengan menggunakan raster calculator pada software ArcGIS. Untuk suhu permukaan laut, didentifikasi dengan adanya front (suhu rendah disekeliling suhu tinggi dengan nilai fluktuasi $0,5^{\circ} \mathrm{C}$ ). 


\section{Data Tangkapan Ikan Tongkol}

Data tangkapan ikan tongkol selama 10 tahun (tahun 2006-2016) didapatkan dari Dinas Kelautan dan Perikanan.

\section{HASIL DAN PEMBAHASAN}

\section{Peta Klorofil-a, Suhu Permukaan Laut dan Prediksi Fishing Ground Pulau Weh}

Berdasarkan peta Fishing Ground yang telah diolah, pada monsun Barat (Desember, Januari, Februari), Bulan Februari merupakan bulan dengan peta Fishing Ground terluas. Rerata luasan area mencapai 455,90 $\mathrm{Km}^{2}$, dengan kisaran nilai klorofil $0,3-1,18 \mathrm{mg} / \mathrm{m}^{3}$ dan rata - rata nilai suhu 28 $29^{\circ} \mathrm{C}$. Peta konsentrasi klorofil-a, SPL dan daerah yang berpotensi sebagai fishing ground pada Bulan Februari disajikan pada Gambar 2.
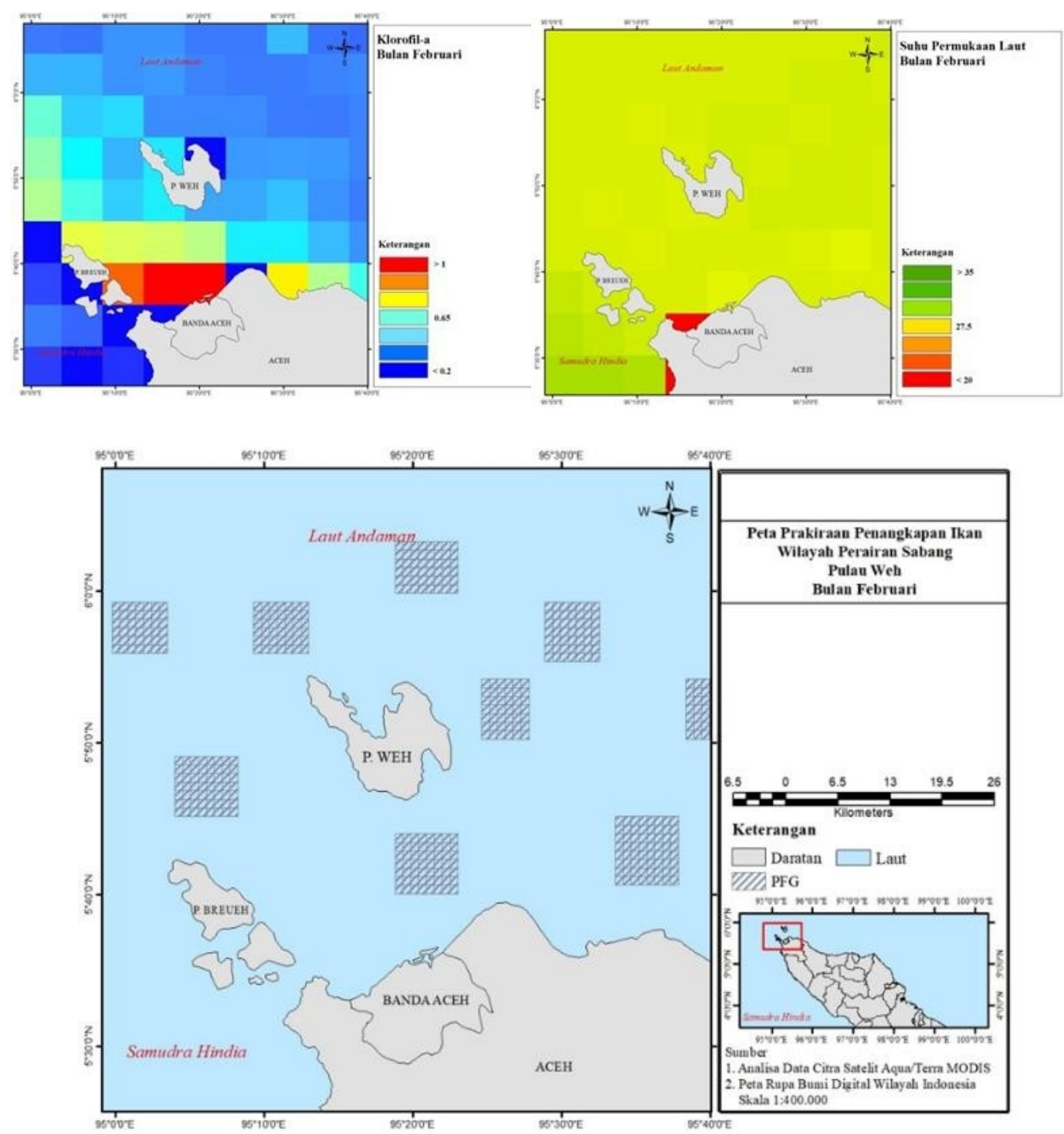

Gambar 2. Peta Klorofil-a, Suhu Permukaan Laut (SPL) dan Prakiraan Penangkapan Ikan Wilayah Perairan Sabang Pulau Weh (berdasarkan Data Bulan Februari 2006 - 2016) 
Sebaliknya pada musim Timur (Juni, Juli, Agustus), bulan Juni merupakan bulan dengan luas area prediksi fishing ground paling sempit. Rerata luas area sebesar yang dapat diprediksi mencapai $190,20 \mathrm{~km}^{2}$, dengan kisaran nilai klorofil-a $0.290-0.583 \mathrm{mg} / \mathrm{m}^{3}$ dan nilai rata-rata suhu $30^{\circ} \mathrm{C}$. Peta konsentrasi klorofil-a, SPL dan daerah yang berpotensi sebagai fishing ground pada bulan Juni disajikan pada Gambar 3.
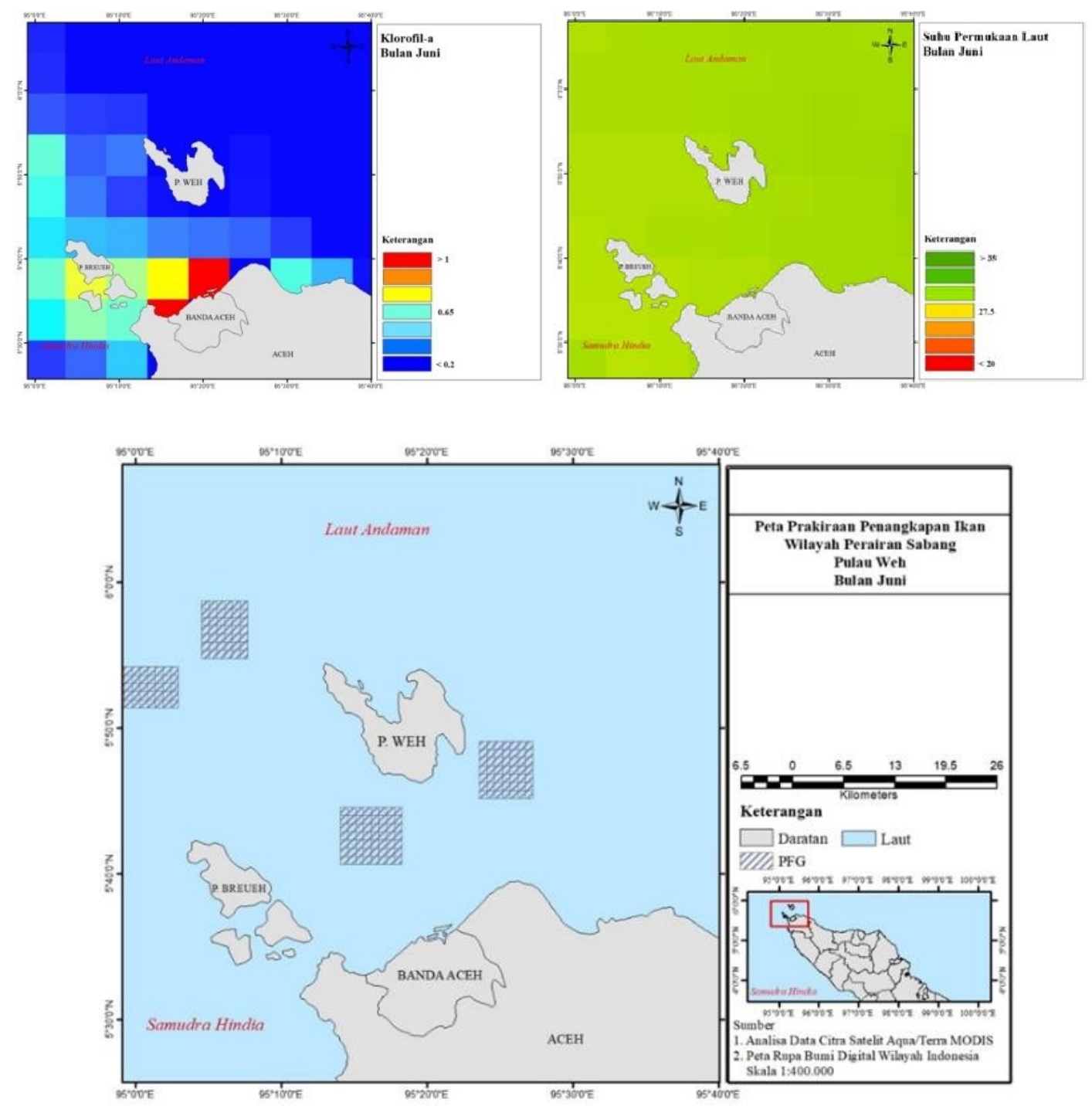

Gambar 3. Peta Klorofil-a, Suhu Permukaan Laut (SPL) dan Prakiraan Penangkapan Ikan Wilayah Perairan Sabang Pulau Weh (berdasarkan data Bulan Juni 2006 - Juni 2016)

\section{Data Angin}

Data angin yang didapatkan dari ECMWF, memperlihatkan pola pergerakan yang sesuai dengan pergerakan Monsun Barat maupun Monsun Timur. Dimana pada Musim Barat (Desember, Januari, Februari), angin bergerak dari utara Asia dan melewati Samudra Hindia menuju Australia. Pada Monsun Timur, pergerakan angin juga menuju Timur Laut, dengan pergerakan dari Benua Australia menuju arah Utara Asia. Pola Angin yang terjadi digambarkan menggunakan wind rose, yang disajikan pada Gambar 4-5. 


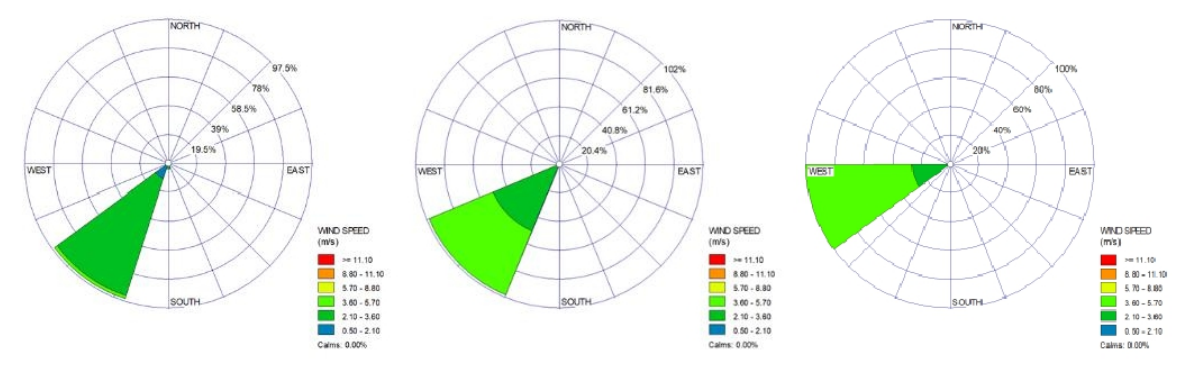

Gambar 4. Wind Rose Pada Monsun Barat (Desember, Januari, Februari) 2006 - 2016
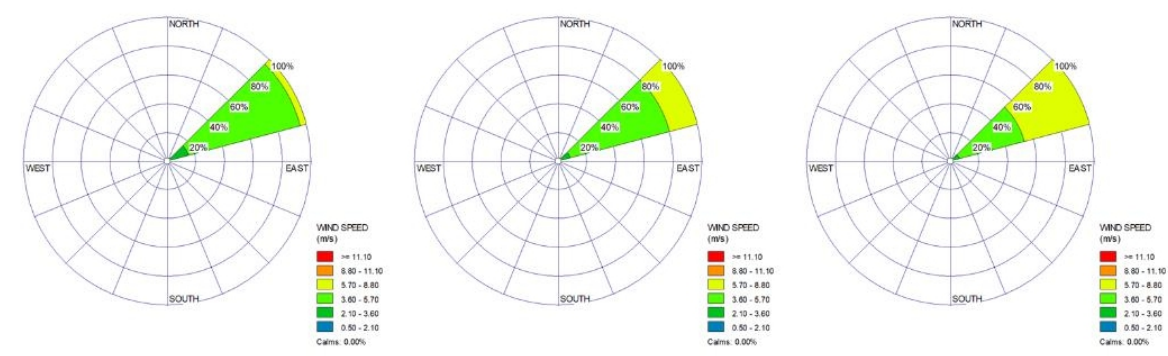

Gambar 5. Wind Rose Pada Monsun Timur (Juni, Juli, Agustus) 2006 - 2016

\section{Hasil Tangkapan Ikan Tongkol Per Kuartal Kota Sabang Selama 10 Tahun}

Data tangkapan ikan tongkol selama 10 tahun yang didapatkan dari Dinas Kelautan dan Perikanan dihitung pada setiap kwartal. Nilai setiap kwartal disajikan pada Tabel 1. Tahun 2013 merupakan tahun dengan jumlah tangkapan ikan tongkol tertinggi, sedangkan tahun 2009 merupakan tahun dengan jumlah tangkapan paling sedikit.

Tabel 1. Hasil Tangkapan Ikan Tongkol Per Kuartal Kota Sabang (Tahun 2006-2016)

\begin{tabular}{cccccc}
\hline \multirow{2}{*}{ Tahun } & \multicolumn{3}{c}{ Tangkapan Ikan Tongkol (Satuan: Ton) } & \multirow{2}{*}{$\begin{array}{c}\text { Total Tangkapan } \\
\text { Ikan }\end{array}$} \\
\cline { 2 - 4 } 2006 & Kuartal I & Kuartal II & Kuartal III & Kuartal IV & 885,9 \\
2007 & 214,2 & 250,1 & 230,5 & 191,1 & 1650,9 \\
2008 & 481,6 & 466,9 & 342,2 & 360,2 & 1605,8 \\
2009 & 457,4 & 437,5 & 350,7 & 360,2 & 383,6 \\
2010 & 63,3 & 115,4 & 82,9 & 122 & 539,8 \\
2011 & 93,9 & 162,5 & 89,6 & 193,8 & 1214,9 \\
2012 & 212,5 & 388,8 & 237,7 & 375,9 & 1463,5 \\
2013 & 174,8 & 407,2 & 364 & 517,5 & 2218,06 \\
2014 & 1071,1 & 444,8 & 320,4 & 381,76 & 2161,83 \\
2015 & 407,27 & 493,9 & 556,6 & 704,06 & 1776,7 \\
2016 & 521,2 & 540,9 & 431,3 & 283,3 & 2215 \\
Rata - Rata & - & - & - & - & 1390,099 \\
\hline
\end{tabular}

\section{Data Luas Area Peta Prediksi Penangkapan Ikan}

Berdasarkan hasil pengolahan data peta fishing ground, luas area rata-rata peta prediksi penangkapan ikan disampaikan pada Tabel 2. Area terluas pada bulan Februari dengan luas area rata - rata 455,90 $\mathrm{km}^{2}$ dan bulan Juni dengan luas area rata - rata paling kecil yaitu 190,20 $\mathrm{km}^{2}$. Data luasan area prediksi tangkapan ikan secara lengkap disajikan pada Tabel 2. 
Tabel 2. Luas Area Peta Prediksi Penangkapan Ikan

\begin{tabular}{ccc}
\hline Bulan & Jumlah Area Tangkapan & Luas Area $\left(\mathrm{Km}^{2}\right)$ \\
\hline Januari & 8 & 278,99 \\
Februari & 9 & 455,90 \\
Maret & 8 & 328,59 \\
Mei & 4 & 254,55 \\
Juni & 4 & 190,20 \\
Juli & 5 & 279,81 \\
Agustus & 7 & 368,20 \\
September & 7 & 376,43 \\
Oktober & 8 & 425,22 \\
November & 7 & 362,95 \\
Desember & 7 & 329,59 \\
\hline
\end{tabular}

\section{PEMBAHASAN}

Variasi klorofil-a bisa digunakan sebagai indikator potensi fishing ground. Menurut Hendiarti et al. (2004) dan Gaol et al. (2004) pada saat klorofil-a tinggi maka potensi area fishing ground juga tinggi. Setelah dilakukan pengolahan data citra di Perairan Sabang Pulau Weh selama 10 tahun dapat dilihat hasil perkiraan penangkapan ikan tongkol setiap bulannya yang menyebar di sekitar Pulau Weh (Gambar 2-3). Saat Monsun Barat menuju peralihan I lebih tepatnya pada bulan Januari terlihat sebaran peta fishing ground lebih banyak tersebar di daerah Barat hingga Barat Laut, Pulau Weh. Pada bulan Februari dan Maret terlihat sebaran peta fishing ground menyebar secara merata di sekitar Pulau Weh dan memiliki potensi penangkapan lebih besar dari bulan sebelumnya (Tabel 1). Saat monsun Timur - peralihan II, lebih tepatnya pada bulan Juni terlihat sebaran peta fishing ground lebih banyak tersebar di daerah selatan Pulau Weh dan potensi penangkapan ikannya sama dengan bulan sebelumnya. Pada bulan Juli terlihat sebaran peta fishing ground lebih banyak tersebar di daerah Barat Laut Pulau Weh dan potensi penangkapan ikannya sama dengan bulan sebelumnya. Pada bulan Agustus hingga Desember terlihat sebaran peta fishing ground menyebar secara merata di sekitar Pulau Weh dan memiliki potensi penangkapan lebih besar dari bulan sebelumnya.

Pada bulan Februari merupakan potensi tertinggi daerah fishing ground dikarenakan saat bulan tersebut memiliki curah hujan yang tinggi, dimana sebaran klorofil-a tersebar banyak di sekitar Pulau Weh dengan nilai yang bervariasi dengan nilai klorofil antara $0,330 \mathrm{mg} / \mathrm{m}^{3}-1,072 \mathrm{mg} / \mathrm{m}^{3}$ dan pada bulan Maret dengan nilai $0,288 \mathrm{mg} / \mathrm{m}^{3}-0,883 \mathrm{mg} / \mathrm{m}^{3}$, dengan sebaran klorofil-a yang tergolong banyak tersebar dan bervariasi nilainya. Hasil ini sesuai dengan penelitian Muklis et al. (2009), di Perairan Aceh yang menyatakan bahwa klorofil-a tinggi ditemukan pada musim Barat-peralihan. Tingginya konsentrasi klorofil-a pada musim peralihan barat-timur berkaitan dengan suplai nutrien dari daratan yang keluar melalui beberapa sungai. Klorofil-a merupakan pigmen hijau yang ditemukan dalam fitoplankton. Kelimpahan fitoplankton akan diikuti oleh zooplankton dan selanjutnya diikuti oleh ikan-ikan pelagis kecil dan besar. Sedangkan pada bulan Juni dan Juli terdapat penurunan potensi penangkapan ikan dengan nilai klorofil yang tergolong kecil, dengan nilai antara $0,290-0,583 \mathrm{mg} / \mathrm{m}^{3}$. Hasil penelitian nilai klorofil-a pada Bulan Juni di Perairan Pulau Aceh sebesar $0,71 \mathrm{mg} / \mathrm{m}^{3}$ (Mursyidin et al., 2015). Berdasarkan Gambar 4, klorofil tersebut hanya tersebar pada bagian Barat Daya hingga Barat Laut pulau Weh, untuk bagian lainnya konsentrasi klorofil yang kecil. Hal ini juga berhubungan dengan Monsun Timur yang berhembus dari Australia menuju utara Asia dengan membawa angin yang bersifat kering, yang menyebabkan terjadinya musim kemarau di Indonesia. Pada bulan Desember terjadi kenaikan potensi penangkapan ikan, dengan sebaran klorofil-a antara $0,149 \mathrm{mg} / \mathrm{m}^{3}-1,340 \mathrm{mg} / \mathrm{m}^{3}$. Hal ini dikarenakan berkaitan dengan terjadinya Monsun Barat, dimana angin bergerak dari Utara Asia menuju Benua Australia.

Berdasarkan data wind rose 10 tahun (Gambar 45) arah angin mengikuti pergerakan angin Monsun Barat dan angin Monsun Timur. Arah angin pada bulan Desember, Januari, dan Februari mengikuti pergerakan angin Monsun Barat melewati Indonesia bagian Barat Laut menuju Australia. 
Hal ini terlihat dari arah angin yang berada di kuadran $3\left(180^{\circ}-270^{\circ}\right)$ dengan kecepatan tertinggi pada bulan Februari, dengan nilai maksimum 5,4495 km/h dan nilai minimum 2,7 km/h.

Arah angin pada bulan Juni, Juli, Agustus, September, Oktober juga mengikuti pergerakan angin Monsun Timur yang berhembus dari Australia melewati bagian Selatan dan Barat Daya Indonesia lalu menuju ke arah Utara. Hal ini yang menyebabkan arah angin yang terdeteksi di stasiun berada di kuadran $1\left(0^{\circ}-90^{\circ}\right)$, dengan kecepatan angin tertinggi pada bulan Agustus dengan nilai maksimum $6,773 \mathrm{~km} / \mathrm{h}$ dan nilai minimum $3,265 \mathrm{~km} / \mathrm{h}$. Arah angin pada bulan Agustus berada di antara $48,05^{\circ}-70,41^{\circ}$.

\section{KESIMPULAN}

Hasil analisis memperlihatkan bahwa faktor klorofil-a, dan angin Monsun baik Musim Barat maupun Musim Timur berpengaruh terhadap hasil tangkapan ikan tongkol di pulau Weh, Kota Sabang. Monsun Barat dan Peralihan 1 (Desember, Januari, Februari, Maret, April, Mei) merupakan musim dengan jumlah tangkapan tinggi. Bulan Februari merupakan memiliki luas area perkiraan tangkapan ikan tinggi mencapai $455,89 \mathrm{~km}^{2}$. Jumlah tangkapan ikan tongkol yang tinggi pada Monsun Barat bertepatan dengan konsentrasi klorofil-a yang tinggi dan suhu permukaan laut yang relatif rendah. Monsun Timur - Peralihan 2 (Juni, Juli, Agustus, September, Oktober, November) merupakan musim dengan jumlah tangkapan ikan yang rendah, dan bulan Juni merupakan bulan dengan luas area perkiraan tangkapan ikan paling rendah yaitu $190,19 \mathrm{~km}^{2}$. Jumlah tangkapan ikan tongkol yang rendah pada Monsun Timur bertepatan dengan konsentrasi klorofil-a yang rendah dan suhu permukaan laut yang relatif tinggi.

\section{Daftar Pustaka}

BPOL. 2016. Modul Pembuatan Peta Prediksi Daerah Penangkapan Ikan. Balai Penelitian dan Observasi Laut, Perancak, Bali.

Girsang H. 2008. Studi Penentuan Daerah Penangkapan Ikan Tongkol Melalui Pemetaan Penyebaran Klorofil-a dan Hasil Tangkapan di Palabuhanratu, Jawa Barat [Skripsi]. Bogor: Departemen Pemanfaatan Sumberdaya Perikanan Fakultas Perikanan dan Ilmu Kelautan Institut Pertanian Bogor.

Habib EY, M, Nofrizal, \& Mubarak. 2019. Sebaran SPL Kaitannya dengan Hasil Tangkapan Ikan Cakalang (Katsuwonus pelamis) Di Perairan Aceh. Marine Fisheries, 10(1): 11-22.

Hendiarti, N, Siegel H, and Ohde T. 2004. Investigation of Different Coastal Processes in Indonesian Waters Using SeaWiFS data, Deep Sea Res, Part II, 5(1):85-97.

Kunarso. 2005. Kajian Penentuan Lokasi-Lokasi Upwelling Di Perairan Indonesia dan Sekitarnya Serta Kaitannya Dengan Fishing Ground Tuna, Thesis, Bidang Khusus Oseanografi Fisis. PS. Oseanografi, Saints Atmosfir dan Seismologi, ITB, Bandung, $250 \mathrm{hlm}$.

Gaol, J.L., Wudianto, B.P. Pasaribu, D, Manurung, and R. Endriani. 2004. The Fluctuation of Chlorophyll-a Concentration Derived from Satellite Imagery and Catch of Oily Sardine (Sardinella lemuru) in Bali Strait. Int. J. Remote Sensing and Earth Science, 1(1):24-30.

Muklis, Gaol, J.L. \& Simbolon, D. 2009. Pemetaan Daerah Potensial Penangkapan Ikan Cakalang (Katsuwonus pelamis) dan Tongkol (Euthynnus affinis) di Perairan Utara Nanggroe Aceh Darussalam. Jurnal Ilmu dan Teknologi Kelautan Tropis, 1(1): 24-32.

Mursyidin, Munadi, K, dan Muchlisin Z.A. 2015. Prediksi Zona Tangkapan Ikan Menggunakan Citra Klorofil-a dan Citra Suhu Permukaan Laut Satelit Aqua MODIS di Perairan Pulo Aceh. Jurnal Rekayasa Elektrika, 11(5) : 176-182.

Sugiyono. 2010. Metode Penelitian Kuantitatif Kualitatif dan RND. Alfabeta. Bandung.

Suryana. 2010. Metodologi Penelitian. Buku Ajar Perkuliahan. Universitas Pendidikan Indonesia, Bandung. 